Research Article

\title{
Seismic Velocity Structure in the Area of the 2007, Mw 8.0, Pisco-Peru Earthquake: Implications for the Mechanics of Subduction in the Vicinity of the Nazca Ridge
}

\author{
I. Bernal $(i D)$ and H. Tavera $(i D)$ \\ Instituto Geofísico del Perú (IGP), Peru \\ Correspondence should be addressed to H. Tavera; htavera@igp.gob.pe
}

Received 29 January 2020; Revised 29 September 2020; Accepted 7 October 2020; Published 6 November 2020

Academic Editor: Veronica Pazzi

Copyright (c) 2020 I. Bernal and H. Tavera. This is an open access article distributed under the Creative Commons Attribution License, which permits unrestricted use, distribution, and reproduction in any medium, provided the original work is properly cited.

\begin{abstract}
In this study, we present a velocity model for the area of the 2007 Pisco-Peru earthquake $(\mathrm{Mw}=8.0)$ obtained using a doubledifference tomography algorithm that considers aftershocks acquired for 6 months. The studied area is particularly interesting because it lies on the northern edge of the Nazca Ridge, in which the subduction of a large bathymetric structure is the origin of geomorphological features of the central coast of Peru. Relocated seismicity is used to infer the geometry of the subduction slab on the northern flank of the Nazca Ridge. The results prove that the geometry is continuous but convex because of the subduction of the ridge, thereby explaining the high uplift rates observed in this area. Our inferred distribution of seismicity agrees with both the coseismic and postseismic slip distributions.
\end{abstract}

\section{Introduction}

The Pisco earthquake occurred on 15 August 2007. It was the largest event $\mathrm{Mw} 8.0[1,2]$ that occurred in central Peru since the 1974 earthquake in Lima ( $\mathrm{Mw}$ 8.1). This event caused casualties (up to 600) and damaged $80 \%$ of the buildings in the area [3]. The rupture of the Pisco earthquake is limited to the north by the 1974 ( $\mathrm{Mw} \mathrm{8.1)}$ Lima earthquake and to the south by the 1996 (Mw 7.7) Nazca earthquake. It has filled a seismic gap previously identified by Tavera and Bernal [4]. The Pisco earthquake is the largest event in the Pisco area since the 1746 great earthquake [5].

This event was notable in many aspects. (i) The rupture consisted of the breakage of two distinct asperities separated temporally by $60 \mathrm{~s}$ of seismic quiescence. Many arguments suggest that the apparent arrest of rupture between the two subevents is due to the propagation of rupture within a creeping patch $[1,6]$. (ii) The largest aftershock following the Pisco earthquake was only $\mathrm{Mw}$ 6.4, which is quite an unusual feature in terms of the size of this event. Bath's law (Báth, [7]) indicated that the difference in magnitude between a main event and its largest aftershock should be close to 1.2. However, in the case of the 2007 Pisco earthquake, this difference is 1.6. As discussed in [1], this discrepancy might disappear considering that the rupture sequence is composed of two distinct events with low magnitude. (iii) The rupture initiated north of the Nazca Ridge and propagated southwards until reaching the northern edge of the Nazca Ridge where it stopped abruptly. Most of the following postseismic slip was located on this site $[6,8]$. This scenario suggests that the Nazca Ridge acts as a barrier for seismic rupture propagation, which is consistent with the low level of seismic coupling, inferred by the inversion of interseismic GPS velocities $[6,9]$. This finding is in agreement with the fact that historical earthquake has propagated through the Nazca Ridge [5].

The Pisco earthquake was followed by a large number of aftershocks: in the first 45 days, about 4500 aftershocks with $\mathrm{Mw}>3$ were recorded by the Instituto Geofísico del Perú (IGP). An accurate location of those aftershocks has not been possible because of the lack of a good velocity model for the area. To improve this situation, 3 months after the event, we have installed 10 seismic stations for 


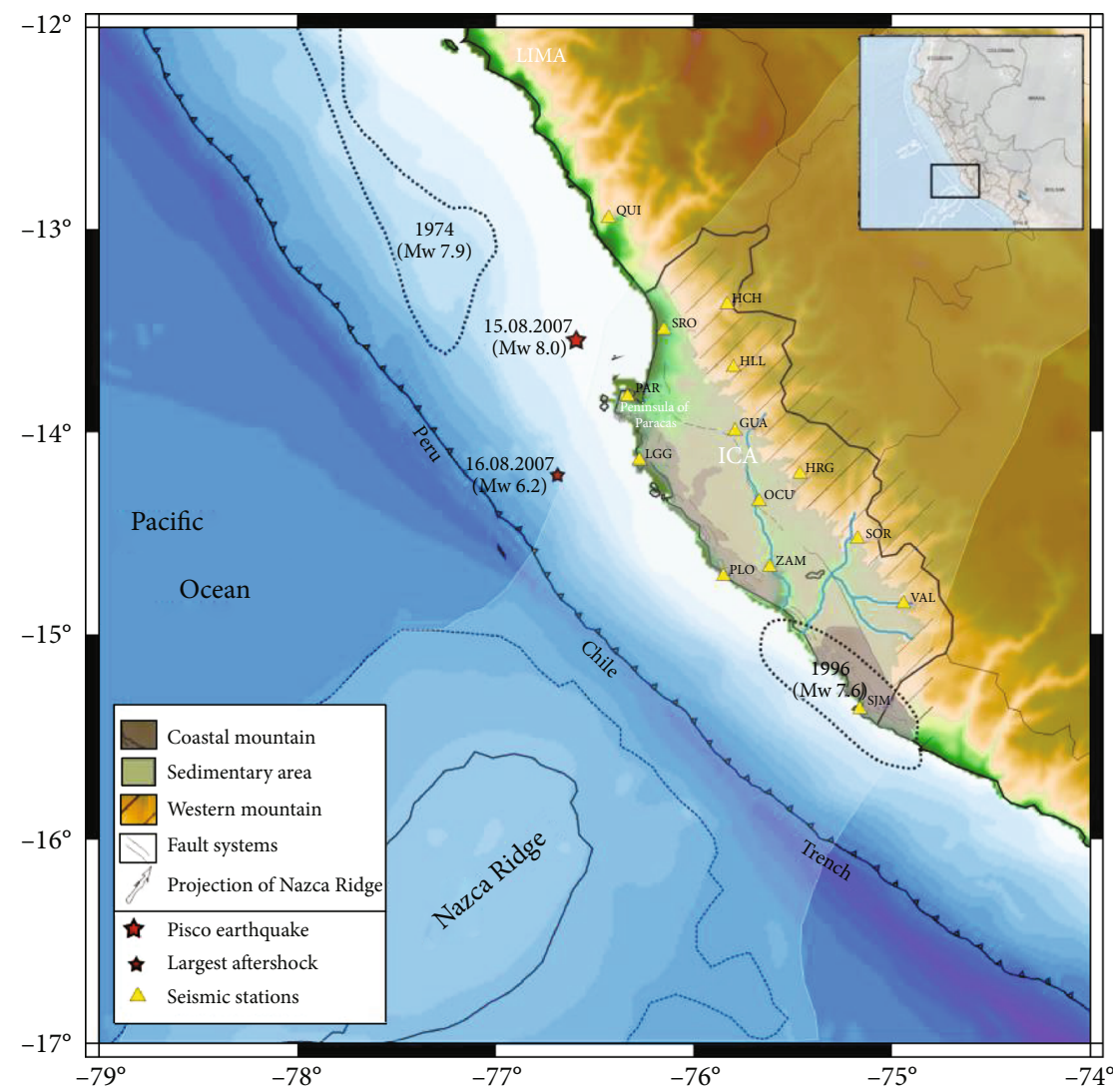

Figure 1: Main tectonic structures of the study area (Ica). The gray zone delimits the coastal mountain range, whereas the light green area delimits the sedimentary area consisting of a longitudinal valley and flatlands. Sloped lines indicate the western mountain range. The fault systems are perpendicular and parallel to the coastlines. The triangles correspond to the seismic stations of our network from December 2007 to May 2008. The dashed white lines indicate the projection of the Nazca Ridge under the study area (South America plates), adapted from [22]. The dashed black lines indicate the rupture area of the 1974 and 1996 earthquakes. Stars correspond to the location of the Pisco earthquake (main event) and the largest aftershock.

a total duration of 6 months in the rupture area. This temporary network was complemented by four permanent stations of the IGP network (QUI, PAR, GUA, and ZAM). The aftershocks recorded by this network of 14 stations (Figure 1) were used to infer a 3D seismic velocity model of the area and relocalization of those events, using a double-difference tomography [10]. Thus, we can accurately determine the geometry of the subduction slab in the vicinity of the Nazca Ridge, as well as the heterogeneity of the subduction slab to the south of the area of rupture. The role of this megastructure on the mechanics of the seismic cycle in this area will be further discussed.

\section{Data and Method}

2.1. Data. Our seismic network operated from December 2007 to May 2008. The 10 stations of the temporary network were three-component short-period seismometers L-22 $(2.0 \mathrm{~Hz})$ and L-4 $(1.0 \mathrm{~Hz})$ with Geostar 16-bit digitizers. The four permanent stations of the IGP network were one-component, short-period Kinemetrics (KMI-SS1) together with a 16-bit digital recorder ACQ. During our survey period of 6 months, more than 3000 aftershocks (with $1.0<\mathrm{ML}<5.0$
) were recorded by at least three seismic stations (Figure 2). Those events were initially located using HIPO inverse [11] considering a $1 \mathrm{D}$ velocity model routinely used by IGP ([12]; Lindo et al., [13]). This velocity model was adjusted from 220 events recorded by a temporary network and the inversion of arrival time.

An initial hypocenter location for the inversion was reduced to 880 events for this study. Many of the excluded events that did not meet the selection criteria considered in this study are as follows: (i) the events need to be recorded by at least four seismic stations, (ii) the root mean square (rms) between the predicted and observed arrival times needs to be less than $0.8 \mathrm{~s}$, (iii) the condition factor (the ratio between the highest and the lowest elements of the matrix of partial derivatives) must be less than 100 to ensure the stability of the inversion, and (iv) at least two arrival times for the $\mathrm{S}$ wave at different stations are needed to strengthen the vertical localization of the seismic events. The goal of the selection criteria is to eliminate aftershocks with large mistakes in its parameters, so they do not affect the inversion process. Differential times were calculated for event pairs separated by less than $10 \mathrm{~km}$ for all stations less than $200 \mathrm{~km}$ from the particular cluster centroid. The use of such 


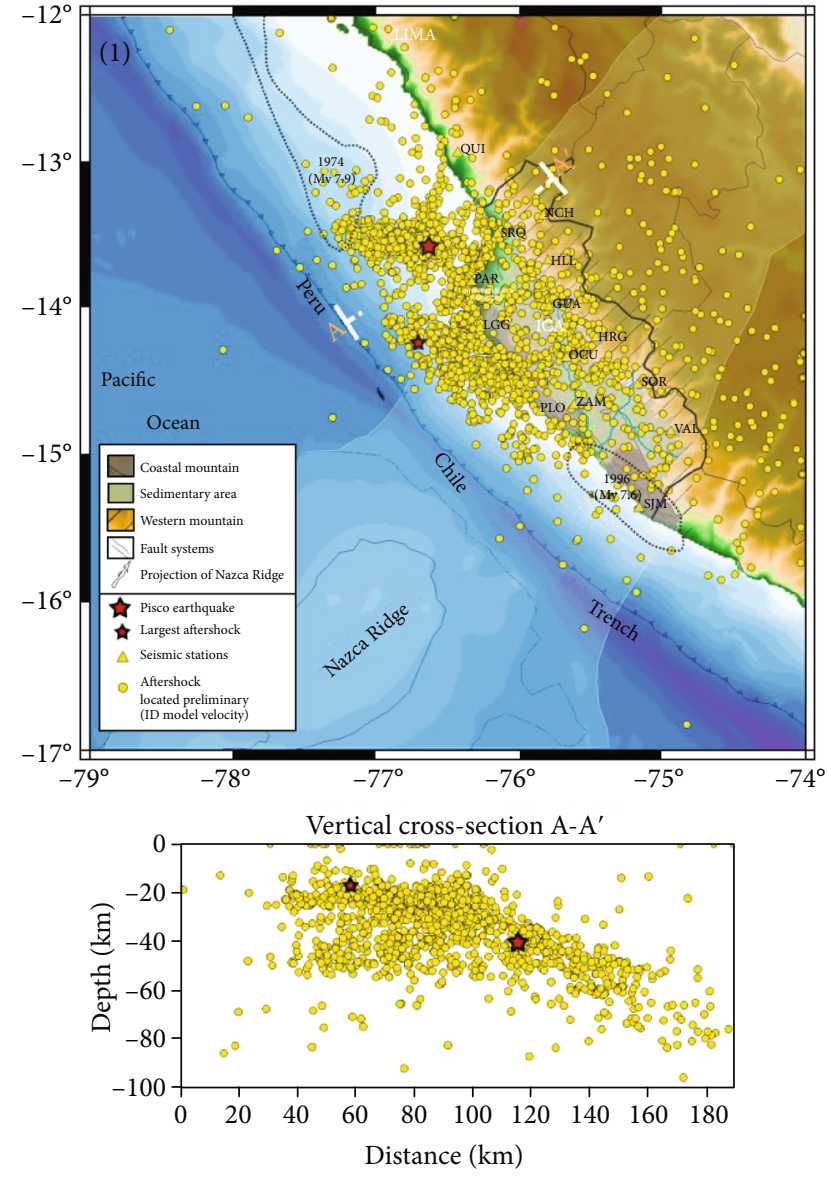

(a)
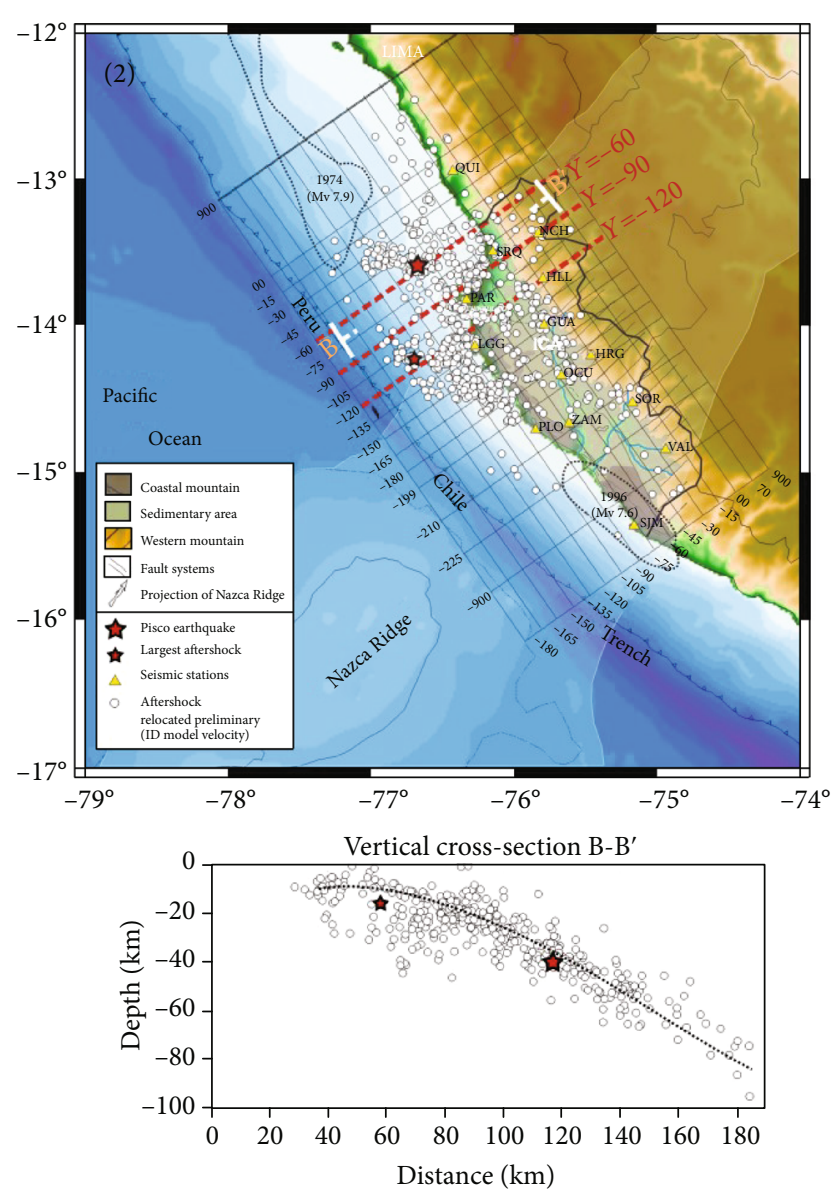

(b)

Figure 2: Aftershock distribution map for the Pisco earthquake registered from December 2007 to May 2008. The large red star corresponds to the main event epicenter, whereas the small star corresponds to the large aftershock. (a) Preliminary aftershock distribution map using the 1D velocity model [12] and its respective seismic profile A-A'. (b) Relocated aftershock distribution map using the 3D velocity model (TomoDD), and its respective seismic profile B-B'. The map presents the $15 \mathrm{~km}$ grid that was used on the inversion process to obtain the $3 \mathrm{D}$ velocity model and aftershock relocation.

a maximum distance criterion reduces the total number of event pairs, but it is justified because the correlation between arrival times from different events typically decreases rapidly with increasing interevent separation.

These derived differential times were weighted based on the quality of the arrival time measurements. Catalog-based differential times (CTDT) were also calculated between closely spaced events from manually selected $\mathrm{P}$ and $\mathrm{S}$ phase times. Absolute arrival times and the differential times (CTDT) were simultaneously inverted using a doubledifference tomography-TomoDD ([10]) in an iterative least-squares procedure, which uses the LSQR method [14].

2.2. TomoDD Algorithm. To infer the regional velocity model and precisely relocate the aftershocks, we used the TomoDD algorithm. This method was developed by [10] based on the HypoDD software of [15]. Unlike other tomography inversion methods, TomoDD uses both the absolute and relative arrival times of the $\mathrm{P}$ and $\mathrm{S}$ waves, ensuring high accuracy in the determination of the hypocentral parameters. TomoDD is based on the underlying idea that the hypocen- tral distance between a pair of events is smaller than the event-station distance. TomoDD minimizes the residual between the observed and predicted arrival times considering each pair of events for a given station, iteratively solving for the relative position vector between hypocenters. The TomoDD algorithm uses a pseudobending ray-tracing theory to compute the ray path between events and stations [16]. The inversion procedure uses a variable weighting procedure. The first inversion is performed by placing a large weight (1.0) on the absolute arrival times and a small weight $(0.1)$ on the relative arrival times. The obtained model serves as input to a second inversion, in which the relative arrival times have now a large weight (1.0) and absolute arrival times are time penalized $(0.1)$. The resulting model will serve as input to the final step of the inversion. The absolute arrival times and the differential times (CTDT) are combined and simultaneously inverted using TomoDD [10] in an iterative least-squares procedure, which utilizes the LSQR method [14].

The $\mathrm{P}$ wave and $\mathrm{S}$ wave velocities derived by Dorbath [12] were used to form the initial velocity model for the travel time calculations. We used their velocities for building a finer 

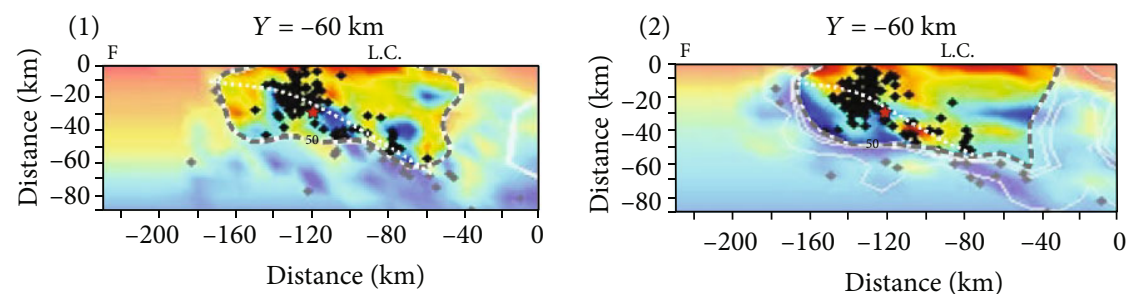

(a)
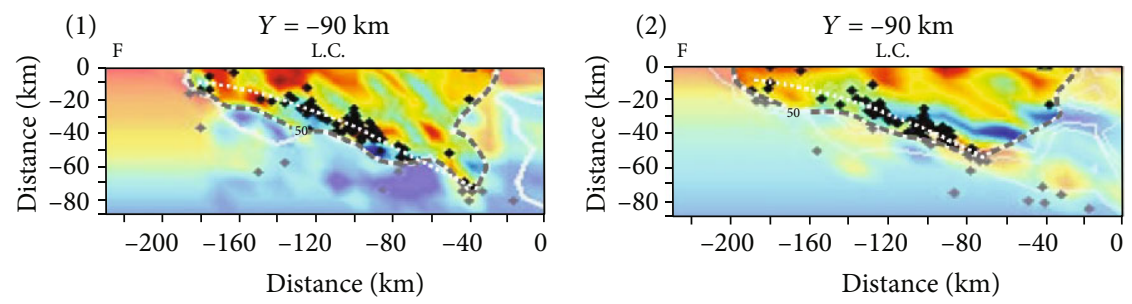

(b)
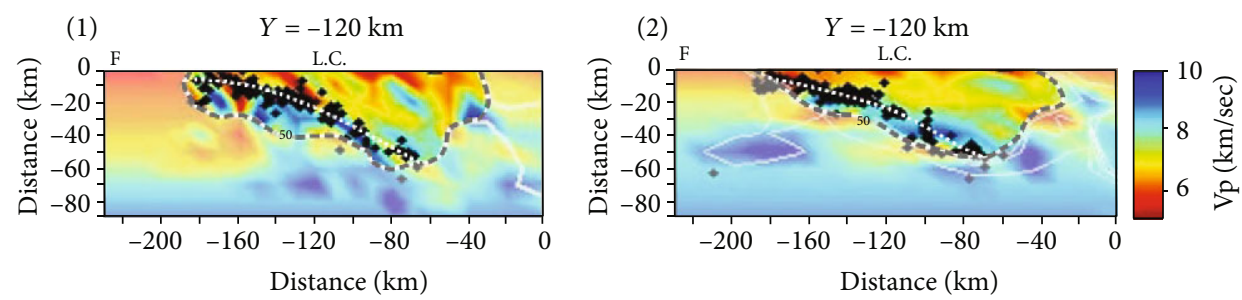

(c)

FIgURE 3: Evolution of the ( $\mathrm{Vp})$ velocity model and relocated hypocenters through the inversion TomoDD, obtained for the vertical crosssections $Y=-60 \mathrm{~km}(\mathrm{a} 1, \mathrm{a} 2), Y=-90 \mathrm{~km}(\mathrm{~b} 1, \mathrm{~b} 2)$, and $Y=-120 \mathrm{~km}(\mathrm{c} 1, \mathrm{c} 2)$ perpendicular to the trench axis, located to the north, center, and south of the Paracas Peninsula. Left: Velocity model obtained after the first iteration. Right: Final velocity model obtained after 30 iterations (last). DWS $=50$ (derivative weight sum) roughly defines the limit between the high- and low-resolution areas (dashed gray line); the tendency of hypocenter locations is shown by the dashed white lines, and the red star corresponds to the main event epicenter.

grid (Figure 2) to encompass our aftershock zone. According, the checkerboard test, the best compromise between accuracy and fineness of the inversion grid had a minimum grid spacing of $15 \mathrm{~km}$ along the $x$ - and $y$-axes in the section of the inversion volume with the highest ray path coverage. Following 30 iterations of the inversion procedure, the rms of the CTDT decreased to $70 \%$.

Figure 2 shows the relocated events projected onto a depth cross-section with a strike of N45E. More than $60 \%$ of the relocated events occur above $30 \mathrm{~km}$ depth and its spatial distribution. The high relative precision of the relocated aftershocks reveals details of the slab geometry. As a by-product, we also obtained information about the influence of the Nazca dorsal in the vicinity of the main event and aftershocks, as well as the geomorphology of the slab structure in this region.

\section{Results}

The algorithm application allows obtaining the 3D seismic velocity structure and relocated aftershocks, then detailed results from each sections.

Figure 3 corresponds to the vertical cross-sections $Y=-$ $60 \mathrm{~km}, Y=-90 \mathrm{~km}$, and $Y=-120 \mathrm{~km}$, traced perpendicular to the trench, located to the north, central, and south of the
Paracas Peninsula (for its orientation and location, see Figure 2(b)), through the relocated hypocenters with the velocity model obtained by TomoDD, after typically 30 iterations, which obtained the final model as observed in Figure 3. This first model (Figure 3(a1), (b1), and (c1)) shows low velocities in the upper part of the model and final model as observed in Figure 3((a2), (b2), and (c2)), where the upper part of the model shows particularly low velocities $(\mathrm{Vp}<7 \mathrm{~km} / \mathrm{sec}$ ), up to a depth of $20 \mathrm{~km}$ according to the cross-section (a2), located to the north of the projection of the Nazca Ridge and high velocities ( $\mathrm{Vp}>7 \mathrm{~km} / \mathrm{seg}$ ) upon the projection of Nazca Ridge. In the cross-sections (b2) and (c2), the replicas are distributed following a vertical trend unlike that observed in (a2) that shows a concentration of aftershocks. The white curves in Figure 3 correspond to the isocontour 50 of the derivative weight sum (DWS) [17]. The DWS $=50$ isocontour roughly defines the limit between high- and low-resolution areas.

Figure 3 shows the seismic velocities in the area of the Pisco earthquake, and relocated aftershocks are shown (diamonds). Aftershocks occurred mainly like a swarm between depths of 10 and $30 \mathrm{~km}$. According to this result, the base of the Moho corresponds roughly to a depth of $20 \mathrm{~km}$, where most aftershocks seem to stand in areas of high $\mathrm{P}$ wave velocities. Such a feature would be expected of seismic events to 


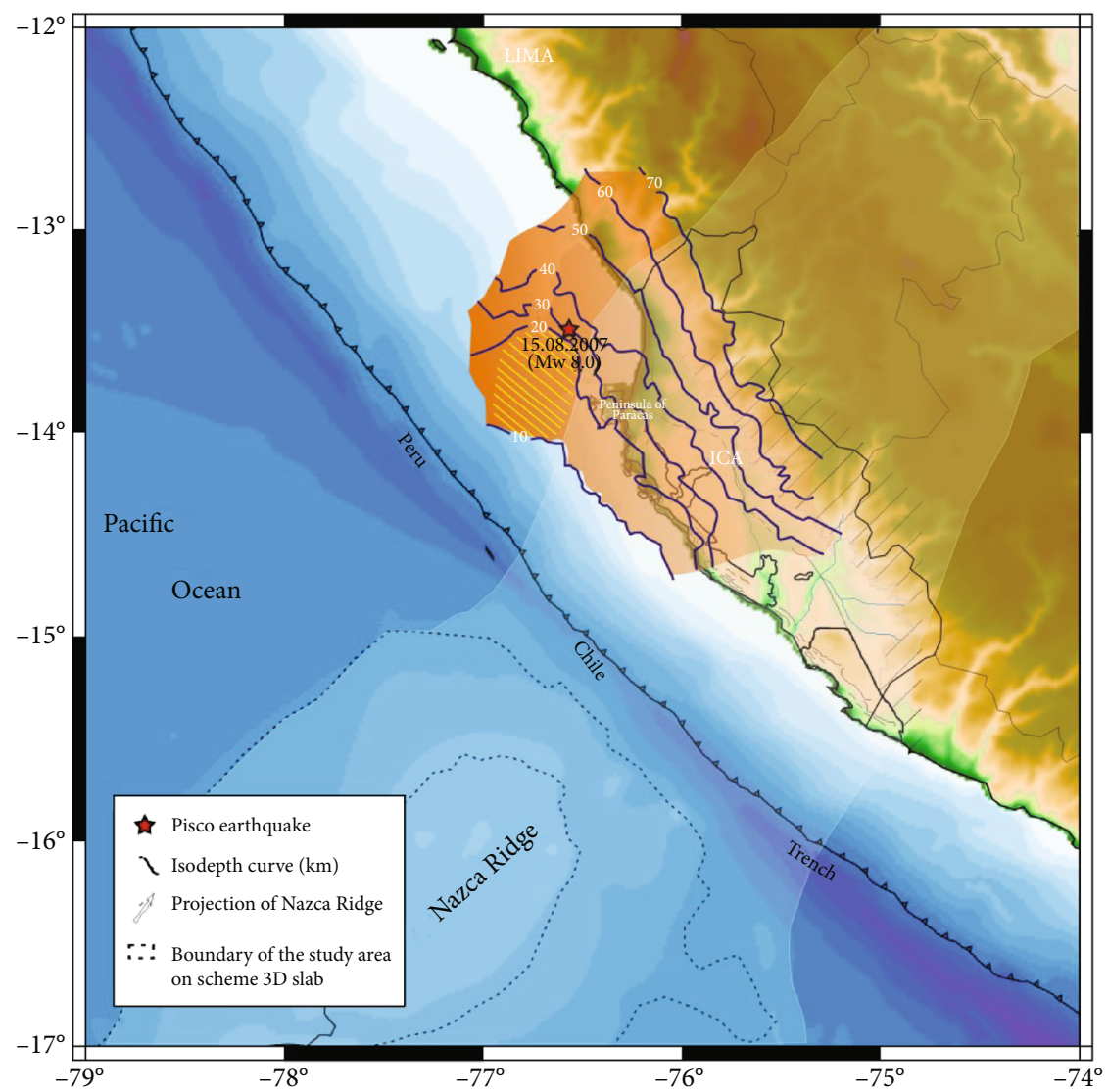

(a)

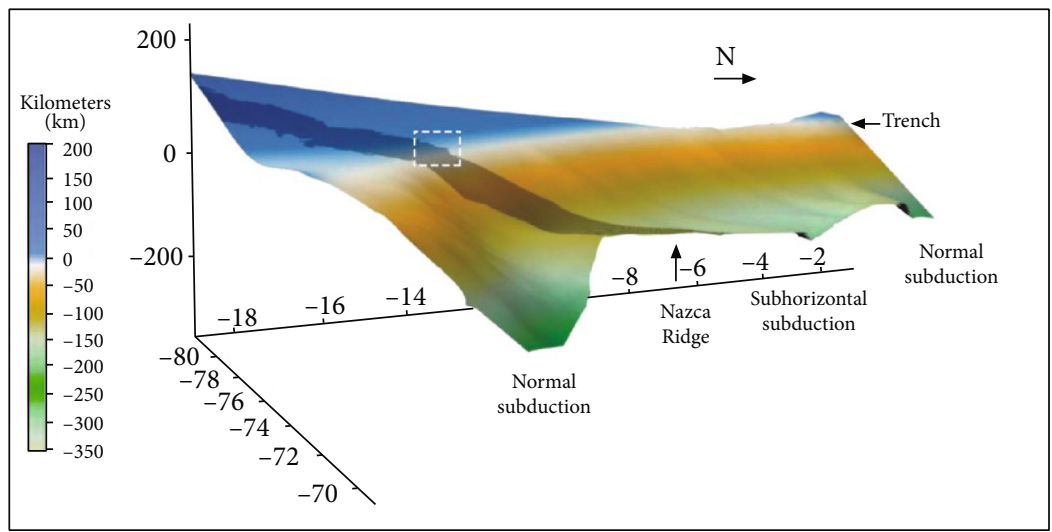

(b)

Figure 4: Geometry of the subduction slab in the area of the Pisco earthquake. (a) The dark blue lines show the isocontours of the slab geometry every $10 \mathrm{~km}$ of depth. The dashed lines extend toward the continent of the axis of the $3 \mathrm{~km}$ bathymetric contour of the Nazca Ridge, and the yellow lines define the convex area of the slab. (b) The white square shows the area of study on the geometry of the slab subduction in the Peru region.

occur in the slab; however, these aftershocks show an apparent seismic spread at depths less than $45 \mathrm{~km}$ probably because of a flexure of the slab rather than of the presence of a wide deformation zone.

\subsection{Geometry of the Slab in the Vicinity of the Nazca Ridge.} The relocated aftershocks are used to map the fault geometry of the slab near the northern edge of the Nazca Ridge. Start- ing from the 12 sections perpendicular to the trench taken and considering the tendency of the depth distribution of the aftershocks, we can define the geometry of the slab. The contour (blue lines) of the final geometry, separated by a depth of $10 \mathrm{~km}$, is shown in Figure 4(a).

The most striking feature of this geometry of the slab is continuous; although it is convex near the trench, its edge is aligned with the $3 \mathrm{~km}$ bathymetry contour of the 


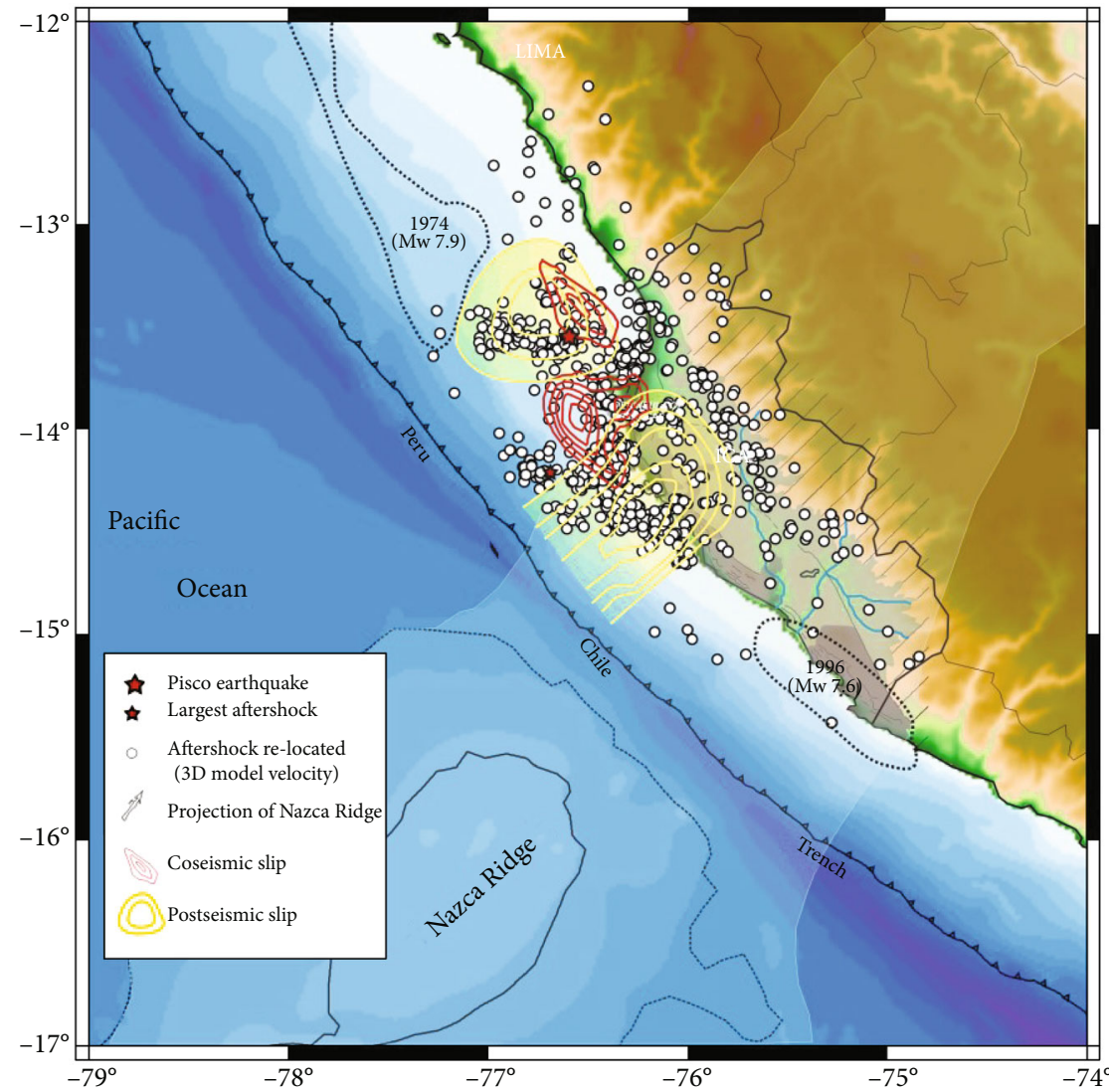

Figure 5: Comparison of the aftershock distribution with coseismic (red contour) and postseismic (yellow contour) slip distribution. The distribution of aftershocks is shown for reference.

Nazca Ridge [18] (dashed line on Figure 1). The flexure decreases with increasing distance from the trench, supporting the hypothesis that the subduction of the Nazca Ridge is causing this geometric change [19] (Figure 4(b)).

The inferred geometry is supported mostly by the two earthquake clusters near the Pisco epicenter and near the Nazca Ridge. The latter is more superficial than the first. Given that both centers of each cluster stand roughly at the same distance from the trench, the geometry of the subduction plane presents lateral changes on both sides of the Nazca Ridge.

The change in slab geometry explains the difference between the tendencies observed along the sections perpendicular to the trench axis. As shown in Figure 3, aftershocks are more scattered along section $(\mathrm{a} 2)(Y=-60 \mathrm{~km})$ than in sections (b2) $(Y=-90 \mathrm{~km})$ and $(\mathrm{c} 2)(Y=120 \mathrm{~km})$. If the geometry of the plane is changing at the level of sections (a2) and (b2), then the cross-section is no longer perpendicular to the actual plane of the subduction. Aftershocks are now projected along a plane oblique to the slab geometry, inducing a higher scattering of the aftershocks along section (a2).

The shape in the slab plane is not symmetric with the respect to the ridge axis. This result is unsurprising because the tectonics of the area are not symmetric: north of it is influenced by the recent passage of the Nazca Ridge, whereas the subduction south of the ridge has not yet been affected.
Our results show a peculiar feature; specifically, the slab geometry appears smoother south of the ridge than north of it.

\section{Discussions}

Figure 5 shows the coseismic and postseismic slip distributions together with the spatial distribution of the aftershocks. The coseismic model is from [1], and it was obtained considering the teleseismic data, InSAR data, tsunami data, and field measurements. The postseismic model is from Perfettini et al. [6] and was obtained considering postseismic continuous GPS measurements. Both models are well constrained and consistent with each other. Postseismic slip is located on the edge of coseismic slip and is higher near the areas of maximum coseismic slip (i.e., in the southern edge of rupture).

Our distribution of aftershocks is consistent with the coseismic model proposed by Sladen et al. [1] because the aftershocks are concentrated on the border of regions of high coseismic slip. Our aftershock distribution is also consistent with the idea that after slip drives aftershocks ([20], 2007; Savage and Yu, 2008; [21]) because most of the seismicity is located in the vicinity of postseismic patches. The density of aftershocks and the postseismic slip distribution both show two peaks: one near the hypocenter and another in the continuation of the Nazca Ridge, south of the domain. 
Another intriguing feature discussed in Sladen et al. [1] and Perfettini et al. [6] is that peak aftershock activity is not located between the two asperities, where some of the maximum coseismic stresses must have been reached. As discussed by these authors, the existence of postseismic slip in this area may suggest the existence of a creeping patch linking the two seismic asperities. This narrow patch (a few tens of kilometers) may have slowed down the rupture, explaining the time delay between the two subevents and the slow apparent rupture velocity $<1.5 \mathrm{~km} / \mathrm{seg}$ [1]. If the interasperity region slipped during the main event, it released a significant amount of stress and is less likely to produce aftershocks, being consistent with the decreasing of aftershocks in this region. One should not rule out the alternative scenario, which is that the Pisco event consists of two separate ruptures: the second one is dynamically triggered, with a certain delay, by the first event. However, in this case, the region connecting the two coseismic asperities should be a site of high aftershock production because it is caught between two large ruptures. The fact that the aftershock activity is moderate favors the scenario of a creeping band.

\section{Conclusions}

The velocity $3 \mathrm{D}$ model in the area of the 2007, $\mathrm{Mw}=8.0$, Pisco (Peru) earthquake obtained using TomoDD and the relocation of aftershocks acquired during 6 months using a 10 temporary seismic station network have permitted us to determine high- and low-velocity zones, as well as to define better the slab geometry. The studied area is particularly interesting because it lies on the northern edge of the Nazca Ridge, a large subduction structure responsible for many geomorphological features of the central coast of Peru.

Relocated seismicity allows us to infer the geometry of the subduction slab on the northern flank of the Nazca Ridge. In the north of the Paracas Peninsula and at the northern limit of the Nazca Ridge projection, the Moho base corresponds roughly to a depth of $20 \mathrm{~km}$, with typical $\mathrm{P}$ wave velocities of $5.5-6.5 \mathrm{~km} / \mathrm{s}$, respectively. These values are in contrast to what was observed in the south of the Paracas Peninsula where the Moho corresponds roughly to a depth between 20 and $30 \mathrm{~km}$, with an increase in $\mathrm{P}$ wave velocities $(8 \mathrm{~km} / \mathrm{s})$. We show that the geometry of the slab is continuous in its subduction process, but it shows a convexity on the northwest side of this structure, due to the subduction of the Nazca Ridge. The subduction starts under the trench and dips at $30^{\circ}$ approximately up to a depth of $60 \mathrm{~km}$. Finally, the distribution of aftershock coincides with the coseismic and postseismic slip distributions, a fact that favors the presence of a progressive alignment of the aftershock in this area.

\section{Data Availability}

The data used in this study are available from the corresponding author upon request.

\section{Conflicts of Interest}

The authors declare that there are no conflicts of interest regarding the publication of this paper.

\section{Acknowledgments}

This research was supported by the Geophysical Institute of Perú (IGP) and Institut de Recherche pour le Developpement (IRD). We would like to thank Dra. Catherine Dorbath by training in the use of algorithm TomoDD and their valuable contributions to the manuscript. I particularly thank Dr. Hugo Perfettini for your support, advice, and contribution in my professional life.

\section{References}

[1] A. Sladen, H. Tavera, M. Simons et al., "Source model of the 2007 Mw 8.0 Pisco, Peru earthquake: implications for seismogenic behavior of subduction megathrusts," Journal of Geophysical Research, vol. 115, article B02405, 2010.

[2] H. Tavera, I. Bernal, and H. Salas, El Terremoto de Pisco del 15 de Agosto de 2007: Aspectos Sismol'ogicos, Volúmen Especial del IGP, Instituto Geofísico del Perú, 2008.

[3] R. D'Ercole, J. Chandes, H. Perfettini, and L. Audin, Le S'eisme de Pisco du 15 Aoilt 2007: Entre Urgence et Reconstruction, EchoG'eo, 2007, http://echogeo.revues.org/index2109.

[4] H. Tavera and I. Bernal, "Distribución Espacial de Áreas de Ruptura y Lagunas Sísmicas en el Borde Oeste del Perü," in Volumen Especial N6 Alberto Giesecke Matto, vol. 6, pp. 89102, Sociedad Geológica del Perü, 2005.

[5] L. Dorbath, A. Cisternas, and C. Dorbath, "Assessment of the size of large and great historical earthquakes in Peru," Bulletin of the Seismological Society of America, vol. 80, no. 3, pp. 551576, 1990.

[6] H. Perfettini, J.-P. Avouac, H. Tavera et al., "Seismic and aseismic slip on the Central Perú megathrust," Nature, vol. 465, no. 7294, pp. 78-81, 2010.

[7] M. Bath, "Lateral inhomogeneities of the upper mantle," Tectonophysics, vol. 2, no. 6, pp. 483-514, 1965.

[8] D. Remy, H. Perfettini, N. Cotte et al., "Postseismic relocking of the subduction megathrust following the 2007 Pisco, Peru, earthquake," Journal of Geophysical Research, vol. 121, no. 5, pp. 3978-3995, 2016.

[9] M. Chlieh, H. Perfettini, H. Tavera et al., "Interseismic coupling and seismic potential along the Central Andes subduction zone," Journal of Geophysical Research, vol. 116, no. B12, article B12405, 2011.

[10] H. Zhang and C. H. Thurber, "Double-difference tomography: the method and its application to the Hayward fault, California," Bulletin of the Seismological Society of America, vol. 93, no. 5, pp. 1875-1889, 2003.

[11] F. W. Klein, “User's guide to HYPOINVERSE-2000, a Fortran program to solve for earthquake locations and magnitudes," U. S. Geol. Survey Open-File Rept. 02-171, 2002.

[12] C. Dorbath, L. Dorbath, A. Cisternas et al., "On crustal seismicity of the Amazonian foothill of the Central Peruvian Andes," Geophysical Research Letters, vol. 13, no. 10, pp. 1023-1026, 1986.

[13] R. Lindo, A. Cisternas, L. Dorbath, C. Dorbath, and L. Rivera, "Seismotectonics of the central Peruvian Andes from precise 
seismological data," in Symposium International G'eodynamique Andine 2nd, pp. 103-106, Oxford, Inglaterra, 1993.

[14] C. C. Paige and M. A. Saunders, "Algorithm 583: LSQR: sparse linear equations and least squares problems," ACM Transactions on Mathematical Software, vol. 8, no. 2, pp. 195-209, 1982.

[15] F. Waldauser and W. Ellsworth, "A double-difference earthquake location algorithm: method and application to the northern Hayward fault, California," Bulletin of the Seismological Society of America, vol. 90, no. 6, pp. 1353-1368, 2000.

[16] J. Um and C. H. Thurber, "A fast algorithm for two-point seismic ray tracing," Bulletin of the Seismological Society of America, vol. 77, pp. 972-986, 1987.

[17] C. H. Thurber, "Earthquake locations and three-dimensional crustal structure in the Coyote Lake area, Central California," Journal of Geophysical Research, vol. 83, pp. 8226-8236, 1983.

[18] A. Hampel, "The migration history of the Nazca Ridge along the Peruvian active margin: a reevaluation," Earth and Planetary Science Letters, vol. 203, no. 2, pp. 665-679, 2002.

[19] I. Bernal, Aproximación a un Modelo Detallado de la Sismicidad en el Perú: Características y Evaluación de la Energía Sísmica Liberada, Tesis de Ingeniero, UNSA, 2002.

[20] H. Perfettini and J. P. Avouac, "Stress transfer and strain rate variations during the seismic cycle," Journal of Geophysical Research, vol. 109, no. B6, article B06402, 2004.

[21] J. Savage and J. Langbein, "Postearthquake relaxation after the 2004M6 Parkfield, California, earthquake and rate-and-state friction," Journal of Geophysical Research, vol. 113, no. B10, 2008.

[22] W. Spence, C. Mendoza, E. R. Engdahl, G. L. Choy, and E. Norabuena, "Seismic subduction of the Nazca Ridge as shown by the 1996-97 Peru earthquakes," Pure and Applied Geophysics, vol. 154, no. 3-4, pp. 753-776, 1999. 